TAX COMPLIANCE BY THE VERY WEALTHY: RED FLAGS OF RISK

John Braithwaite, Yvonne Pittelkow and Robert Williams

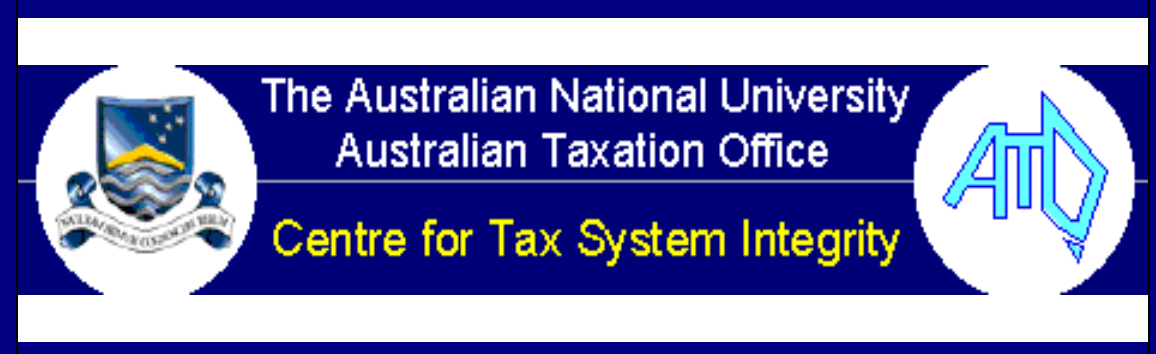

WORKING PAPER No 22

September 2001 


\section{TAX COMPLIANCE BY THE VERY WEALTHY: RED FLAGS OF RISK}

John Braithwaite, Yvonne Pittelkow and Robert Williams

SERIES EDITOR

Tina Murphy

Centre for Tax System Integrity Research School of Social Sciences

Australian National University

Canberra, ACT, 0200

ISBN $064276820 \mathrm{X}$

ISSN 1444-8211 
(C) Centre for Tax System Integrity, Research School of Social Sciences, Australian National University 2001

(C) Commonwealth of Australia 2001

National Library of Australia

Cataloguing-in-Publication data:

Braithwaite, J, 1951-.

Tax compliance by the very wealthy: Red flags of risk.

Bibliography

ISBN $064276820 \mathrm{X}$

1. Taxpayer compliance - Australia. 2. Tax evasion -

Australia. 3. Income tax - Australia. I. Pittelkow,

Yvonne. II. Williams, Robert, 1963- . III. Title. (Series:

Working paper (Centre for Tax System Integrity); no. 22).

336.240994

If you would like to make any comments on this working paper please contact the author directly within 90 days of publication.

\section{Disclaimer}

This article has been written as part of a series of publications issued from the Centre for Tax System Integrity. The views contained in this article are representative of the author only. The publishing of this article does not constitute an endorsement of or any other expression of opinion by the Australian National University or the Commissioner of Taxation of the author's opinion. The Australian National University and the Commissioner of Taxation do not accept any loss, damage or injury howsoever arising that may result from this article. This article does not constitute a public or private ruling within the meaning of the Taxation Administration Act 1953, nor is it an advance opinion of the Commissioner of Taxation. 


\section{THE CENTRE FOR TAX SYSTEM INTEGRITY WORKING PAPERS}

The Centre for Tax System Integrity (CTSI) is a specialized research unit set up as a partnership between the Australian National University (ANU) and the Australian Taxation Office (Tax Office) to extend our understanding of how and why cooperation and contestation occur within the tax system.

This series of working papers is designed to bring the research of the Centre for Tax System Integrity to as wide an audience as possible and to promote discussion among researchers, academics and practitioners both nationally and internationally on taxation compliance.

The working papers are selected with three criteria in mind: (1) to share knowledge, experience and preliminary findings from research projects; (2) to provide an outlet for policy focused research and discussion papers; and (3) to give ready access to previews of papers destined for publication in academic journals, edited collections, or research monographs.

Series Editor:

Tina Murphy 


\section{Tax compliance by the very wealthy: Red flags of risk $^{\square}$}

John Braithwaite, Yvonne Pittelkow and Robert Williams

\section{Executive summary}

A study of 235 High Wealth Individuals (HWIs) and the entities they control was undertaken on 1997 and 1998 tax returns. From this data, and using a list of 207 candidate issues, five red flags for overall risk of aggressive tax planning by HWIs were identified. These red flags indicated recurrent risks that can be predicted using different kinds of analyses of overall high risk. The red flag issues were:

- trust distributions (especially capital distributions in cash to the HWI);

- capital loss creation (especially through asset sales, but not revenue loss creation);

- use of an offshore entity in a country that may be a tax haven;

- utilisation of revenue losses via transfers within the group controlled by the HWI; and

- other risks that fall between the cracks of the main issues.

To some degree, these results are only of historical interest as some of the risks associated with these issues have been reduced by recent Australian corporate tax reforms. With the exception of the last red flag, it could be said that the red flags highlight fundamental issues rather than issues that are believed to be symptomatic of deeper problems - such as converting activities undertaken for private pleasure into tax deductions (for example pleasure craft, horse breeding and racing).

The surprisingly strong and robust predictive power of 'other' issues is not interpreted as an anomaly, but rather as suggesting an evolutionary ecology of aggressive tax planning. Tax planning strategies that everyone, particularly the Tax Office, knows about will not be the most lucrative. While there will be recurrent predation strategies, the best new strategies will

\footnotetext{
${ }^{1}$ The Tax Office acknowledges the comments made in this paper and notes that the conclusions reached are based on aged data. The practices employed by the HWI Taskforce have significantly changed and the conclusions reached may not be the same if this analysis was undertaken today.
} 
be those that are not crowded out by others who use a similar strategy. Minority strategies flourish. We caution therefore against the idea that we can settle in advance all risk categories for aggressive tax planning. We also highlight the importance of intuitive detective work to follow risks that fall between the cracks. This advice follows not only from the importance of the 'other' category, but also the result that the estimated 'objective' dollars at risk added little explanatory power to the ability to predict high risk above and beyond that provided by subjective risk ratings by Tax Office analysts.

It is also argued that it may be more important to consider dollars at risk for certain strategic issues that are not normally red flags for systemic risk, rather than to use the dollars at risk as red flags. For example, negative gearing is not a red flag itself, but exceptionally high levels of negative gearing might raise questions.

\section{The High Wealth Individuals (HWI) Taskforce}

The HWI Taskforce was established by the Australian Taxation Office (Tax Office) in 1996 to enhance compliance management for HWIs - it did this in a way no other tax authority in the world has done before to our knowledge. Traditionally, tax authorities treat individual persons and corporate entities (partnerships, trusts, corporations) as separate taxpayers in their case management. The innovation of the HWI Taskforce was to treat the individual return of a HWI and the entities they control as a single case. In the first year of operation, 180 HWIs received a questionnaire about the groups of entities they control, or from which they received income. These were formalised in subsequent years into expanded returns, called Current Year Data Collection (CYDC) returns. In 1997 and 1998 all HWIs rated as medium or high overall risks (142 and 143 respectively), completed expanded returns for their 2371 and 2599 associated companies, trusts, partnerships or individuals. The level of these individuals' wealth, and the amount of tax they paid, to qualify for this level of scrutiny is confidential, however all those completing expanded returns are extremely wealthy.

The HWI program seems to have increased the amount of tax paid by HWIs. Private companies controlled by individuals in the program paid $17 \%$ less tax than non-HWI companies in 1994, 12\% less in 1995 (the last year before the program was set up), 23\% more in 1996 and 20\% more in 1997 (Braithwaite, 2001: 13). It is believed that this is 
because HWIs are generally more cautious with their tax affairs when they are under the microscope of the HWI program:

'It's the constant surveillance of being on the program that causes compliance...Part IVA is of indeterminate width. It might be applied more aggressively in future. So I advise clients to be careful.'

'Asking the question and getting them to focus their mind on where everything is had an impact' (Braithwaite, 2001: 10).

Another adviser suggested that 'the more information he's (the Commissioner) got, the less aggressive they will be in their tax planning'. What they meant was that notifying X in 1998 reduces the taxpayer's degrees of freedom to re-configure his 1999 affairs in such a way that not-X appears to be the case in 1999. Changes from year to year will be noticed, so HWIs must keep their affairs consistent with the underlying truths of earlier declarations. Also the more holistic approach of the HWI program surveillance means there is a need to work harder at keeping the story about one HWI entity's tax affairs consistent with that of another (Braithwaite, 2001: 11).

\section{The risk ratings}

The data in this report are based on risk ratings of 207 potential risk issues identified from 1997 and/or 1998 tax returns for 235 individual HWIs and the entities they control.

Tax Office analysts might examine as many as 100 expanded returns from all the entities controlled by a HWI, and then in theory rate each of the 207 potential risk issues from 0-10. These ratings are estimates of indications of risk; that is, there is no guarantee that there really is a high risk. Usually an audit would be needed, sometimes even litigation, to establish if the risk was a reality.

As with all risk ratings, the rating estimates used as the basis for this report were checked by a supervisor who may have revised them. For the highest risks, senior taskforce staff would also meet to discuss the analyst's assessment. 
Most of the potential risk issues were not recorded or rated for each HWI. In fact more than half the HWIs in the database had less than ten rated issues. The maximum was fifty-one, and the minimum was one.

This report is concerned with high risk ratings. A rating of 1-3 was defined by the taskforce as a low risk, 4-7 as medium, and 8-10 as high. The defining features of a score of more than 7 in the instructions to analysts are indications of aggressive tax planning 'like significant loss creation', followed by a list of other types of aggressive tax planning or 'further information desirable and would suggest audit action'. Judgments about what is aggressive tax planning are controversial and subjective $\mathrm{e}^{2}$ and there are many reasons to suspect risk ratings as unreliable. ${ }^{\text {In }}$ Ine first part of this report we accept these subjective judgments at face value and use them to predict several criteria of overall risk of the HWI and the entities they control. We then test if the 'objective' criterion of dollars at risk adds any additional information to the more 'subjective' assessment of risk.

The list of 207 potential risk issues used in this analysis has been until now 'highly protected'. While this report will not reveal all the issues in the analysis, it is now possible to release for discussion across the Tax Office and by other tax authorities results that reveal at least the issues that turned out to be important in these analyses. The collection of risk ratings, which are the basis of these analyses, has now been suspended and superseded, so the definition of issues discussed in this report does not provide useful information to tax advisers. Even at a more conceptual level, some of the issues, which we find to be serious risks for 1997-98, are no longer risks as a result of tax reform.

\footnotetext{
${ }^{2}$ For instance, the Tax Office conceives of aggressive tax planning as techniques which:

- undermine the policy intent of the law;

- impact on the integrity of the tax system; and

- erode community confidence in the fairness and the equity of the tax system

Characteristics which mark aggressive tax planning in the Tax Office's view include arrangements which:

- are contrived and artificial in their method of execution;

- are uncommercial from a business or economic perspective;

- are not implemented as specified in contractual and other legal documentation;

- involve round robin finance or circular movement of funds and loans paid off by future earnings;

- involve fraud on the revenue;

- involve permanent tax advantage as distinct from a timing advantage;

- abuse a specific concessional or anti-avoidance provision contrary to the policy underlying the law, and/or

- attempt to reduce the amount of tax properly payable and thus create a revenue risk.

${ }^{3}$ For example, in some instances analysts have included a risk more than once simply because it is feasible that the risk could fall under more than one category.
} 
Our objective with this research is not to revise a list of 207 risk issues that have already been revised, but rather to seize the unique opportunity this data provides to explore which kinds of risk factors predict the existence of the highest levels of overall risk. That is, what are the issues which when rated as an indication of high risk, are a red flag for the existence of many other high risks to the revenue?

\section{What are the most common high risks for HWIs?}

Analysts rated risks relative to other HWIs, not general taxpayers. If this was not the case, virtually all HWIs would have attracted a large number of high risk ratings based simply on their wealth, income levels, and the complexity of their business dealings. This outcome would have been unproductive for determining where the greatest risks lay. As a result, and because not many issues were rated by analysts, it is rare for a HWI to be given a risk rating over 7 on one of the 207 issues.

Table 1 shows that the most common risk issue was rated over 7 in only 12 cases. This was the utilisation of revenue losses (as opposed to capital losses) through transfers within the HWI's group of entities - moving losses to a taxable entity to save tax for that entity. While this is the most common high risk, the second most common - the use of an offshore entity (company, trust, partnership) in an unlisted (that is, low taxed ${ }^{4}$ ) country - received slightly higher risk ratings on average ( $\mathrm{P}<0.01$ on a test of difference in mean rank). Tax authorities are more interested in the extreme risks than in average risks, however, as they only have the resources to deploy audits and other strategies against the highest risks.

There are eight instances of revenue loss creation via research and development (R\&D) deductions. R\&D investment receives a concessional tax treatment and has traditionally been used in tax minimisation arrangements. There are seven instances of 'taxable distributions to a loss entity' which is the inverse of transferring a loss to taxable entity. The term 'distribution' means it is limited to trusts in this instance ${ }^{5}$. If used unscrupulously a loss can

\footnotetext{
${ }^{4}$ The Income Tax Regulations include a 'list' of countries which are considered to have tax systems broadly similar to the Australian system. There are fifty-eight of these 'listed' countries. 'Unlisted' countries are all those that do not appear on the list. They have taxation systems that range from almost comparable to full blown tax havens. Hence 'use of an entity in an unlisted country' would imply that profits were somehow derived in a low taxed country, and that a reduced amount of tax would be paid on them.

${ }^{5}$ Income from trusts comes in the form of a distribution - from companies it is a dividend.
} 
be transferred a number of times and can be used in each entity it passes through. This is known as 'loss cascading' and has been considered a serious risk to the revenue.

Table 1: Most common high risk issues

\begin{tabular}{|c|c|c|c|}
\hline Issue & $\begin{array}{l}\text { No. HWIs with } \\
\text { risk rating }>7\end{array}$ & $\begin{array}{l}\text { Mean risk } \\
\text { rating }\end{array}$ & $\begin{array}{l}\text { Mean dollars } \\
\text { at risk }\end{array}$ \\
\hline $\begin{array}{l}\text { Revenue loss utilisation via intra group } \\
\text { transfer }\end{array}$ & 12 & 4.12 & $\$ 4328670$ \\
\hline $\begin{array}{l}\text { Use of offshore entity in an unlisted } \\
\text { country }\end{array}$ & 8 & 4.40 & - \\
\hline $\begin{array}{l}\text { Revenue loss creation via debt } \\
\text { forgiveness/bad debts }\end{array}$ & 8 & 4.21 & $\$ 5416922$ \\
\hline $\begin{array}{l}\text { Miscellaneous income \& deduction } \\
\text { items - other significant deduction } \\
\text { issues }\end{array}$ & 8 & 4.04 & $\$ 4540784$ \\
\hline $\begin{array}{l}\text { Revenue loss creation via research and } \\
\text { development deduction claims }\end{array}$ & 7 & 5.76 & $\$ 3332722$ \\
\hline $\begin{array}{l}\text { Trust distributions - taxable } \\
\text { distributions to a loss entity }\end{array}$ & 7 & 4.14 & $\$ 5492180$ \\
\hline $\begin{array}{l}\text { Other miscellaneous items - disposal of } \\
\text { significant capital item in review } \\
\text { period (non-assessable profit) }\end{array}$ & 7 & 3.93 & $\$ 15843564$ \\
\hline $\begin{array}{l}\text { Evidence of value shifting or unusual } \\
\text { transactions - means of minimising } \\
\text { income tax in group }\end{array}$ & 6 & 5.22 & - \\
\hline Other miscellaneous items - other & 6 & 4.27 & $\$ 46153472$ \\
\hline $\begin{array}{l}\text { Evidence of value shifting or unusual } \\
\text { transactions - means of minimising } \\
\text { capital gains tax in group }\end{array}$ & 5 & 5.62 & - \\
\hline $\begin{array}{l}\text { Group restructure due to significant } \\
\text { new ventures }\end{array}$ & 5 & 4.24 & - \\
\hline $\begin{array}{l}\text { Trust distributions - distributions from } \\
\text { capital profits reserve }\end{array}$ & 5 & 4.63 & $\$ 3315175$ \\
\hline $\begin{array}{l}\text { Trust distributions - capital distribution } \\
\text { in cash (to the HWI) }\end{array}$ & 5 & 4.73 & $\$ 1196229$ \\
\hline
\end{tabular}


'Debt forgiveness/bad debts' can be used as a technique to create a revenue loss within a group of companies. If one company fails to repay a loan, the company that made that loan can claim it as a bad debt for tax purposes. A bad debt is tax deductable, and, when deductions exceed income, a loss is created. An 'asset disposal' can create a capital loss if the asset is sold for less than the purchase price. Purchase price can be manipulated when the same person ultimately owns the company selling the asset and the company buying the asset. In this way an artificial, and tax deductable, capital loss will be created within the group with no corresponding economic loss to the taxpayer. There are also eight instances of 'other significant deduction issues'. These 'other issues' will be discussed later in this report.

Table 1 also shows the recorded mean dollars at risk (for example the dollars transferred within the HWI group) for each of the common high risk issues. The dollars at risk are the maximum dollars at risk in either 1997 or 1998. Note this is not the dollars at risk when rated over 7; this would be a higher number. Also the mean dollars at risk will include zero entries if they are recorded. However the value of zero may mean no dollars were at risk or that the analyst did not know the dollar amount for some HWI or the entities they control. The high value of $\$ 46$ million for those placed in the miscellaneous 'other' category is significant and will be interpreted later in this report.

Table 2 shows the issues with the highest mean dollars at risk across all 207 issues (as opposed to just the highest risk issues). Transfer of trading stock has an average of $\$ 379$ million at risk. This could be indicative of a transfer pricing issue, but there are only three HWIs with recorded dollars at risk for this issue. In general the estimates of the mean dollars at risk should be treated with caution. For example, if an entity is only partially controlled by a HWI there is a risk that the analyst has included only a portion of the actual risk. 
Table 2: Issues with the highest mean dollars at risk

\begin{tabular}{|c|c|c|c|}
\hline Issue & $\begin{array}{l}\text { No. HWIs with } \\
\text { risk rating }>7\end{array}$ & $\begin{array}{l}\text { Mean risk } \\
\text { rating }\end{array}$ & $\begin{array}{l}\text { Mean dollars } \\
\text { at risk }\end{array}$ \\
\hline $\begin{array}{l}\text { Related party transactions with an } \\
\text { entity in an unlisted country - transfer } \\
\text { of trading stock }\end{array}$ & 0 & 7.00 & $\$ 379333333$ \\
\hline Other miscellaneous items - other & 6 & 4.27 & $\$ 46153472$ \\
\hline $\begin{array}{l}\text { Other miscellaneous items - } \\
\text { finance/treasury issues }\end{array}$ & 2 & 6.25 & $\$ 34848766$ \\
\hline $\begin{array}{l}\text { Capital loss creation via cost base } \\
\text { manipulation }\end{array}$ & 0 & 5.33 & $\$ 22782914$ \\
\hline $\begin{array}{l}\text { Related party transactions with an } \\
\text { entity in an unlisted country - transfer } \\
\text { of assets/property }\end{array}$ & 1 & 4.20 & $\$ 21222264$ \\
\hline $\begin{array}{l}\text { Evidence of dividend streaming within } \\
\text { group companies }\end{array}$ & 0 & 3.67 & $\$ 17485377$ \\
\hline $\begin{array}{l}\text { Related party transactions with an } \\
\text { entity in a listed country - granting of } \\
\text { guarantees }\end{array}$ & 0 & 1.00 & $\$ 17382600$ \\
\hline $\begin{array}{l}\text { Trusts - use of beneficiary loan } \\
\text { accounts (loan source unknown) }\end{array}$ & 3 & 4.28 & $\$ 16152070$ \\
\hline $\begin{array}{l}\text { Other miscellaneous items - disposal } \\
\text { of significant capital items (non- } \\
\text { assessable profit) }\end{array}$ & 7 & 3.93 & $\$ 15843564$ \\
\hline $\begin{array}{l}\text { Companies - use of shareholder loan } \\
\text { accounts (loan source is HWI) }\end{array}$ & 4 & 3.19 & $\$ 10579077$ \\
\hline $\begin{array}{l}\text { Capital loss creation via property } \\
\text { development/ industry }\end{array}$ & 1 & 3.26 & $\$ 10318261$ \\
\hline $\begin{array}{l}\text { Significant franking credit surplus in } \\
\text { group }\end{array}$ & 0 & 3.33 & $\$ 9464742$ \\
\hline $\begin{array}{l}\text { Related party transactions with an } \\
\text { entity in an unlisted country - interest } \\
\text { income }\end{array}$ & 1 & 2.57 & $\$ 9186641$ \\
\hline
\end{tabular}




\section{Predicting high overall risk}

Braithwaite (2001) recommended the Tax Office undertake a cluster analysis of HWI risk factors to show which risks go together, and to reveal systemic risk factors that underpin a variety of seemingly unrelated risks. It was thought that risk clusters might be particularly useful in targeting types of specific purpose audits. For example, risk cluster A should get audit product $\mathrm{X}$; risk cluster $\mathrm{B}$, product $\mathrm{Y}$, etc.

Unfortunately, it eventuated that cluster analysis was inappropriate because, as described above, high-risk ratings are rare events with joint occurrence of any two specific high risks being even lower. In fact there are only two pairs of issues on which four HWIs are both rated as a high risk; all the other pairwise combinations have fewer HWIs sharing a high risk on both issues.

Thus cluster analysis and other pattern finding methodologies are inappropriate for this data set where the emphasis is on high risk. Empirically this suggests that if a 'risky' taxation strategy is measured as a combination of issues assessed as high risk, then these strategies tend to be unique to each HWI or rather shared by very few HWIs.

Due to this finding, analysis was shifted to identifying specific risks that are the best red flags for high overall risk. A 'high' overall risk assessment is defined with a clear action orientation. It means the analyst and their supervisor agree that, all things considered, the application of some kind of audit product is justified. Being placed in the high overall risk category is still a rare event. This happened for only thirty-three HWIs (14\%). There were six HWIs who were not assessed as being in either a high, medium or low risk category, and they were treated as not a high risk.

Table 3 shows the summary from a logistic regression analysis predicting high overall risk. The independent variables in the model are the issues coded as 1 for a high risk (greater than 7) and zero to reflect the notion of a flag (issues coded like this are referred to as flags to differentiate them from rated issues). Because of the interest in choosing a minimum set of 'flags' we chose a stepwise algorithm, which selects the best predictor of likelihood from amongst the flags, then the second-best after the first-best has been included, and so on. The stopping criterion is when the addition of further flags does not sufficiently increase 
predictability of membership into the correct risk group to warrant the added complexity. A scree slope test using the percentage correctly predicted was used to define this stopping point. Thus we attempt to balance statistical and practical significance.

The first predictor of high overall risk is being rated over 7 in the 'other miscellaneous items - other' category - the potential meaning of this finding is discussed in the next section ${ }^{6}$. The issue rated over 7 with the next most predictive value in this model is 'use of an offshore entity in an unlisted country'. We might assume that ratings over 7 will mostly be incurred when there is concern that the unlisted country is a tax haven. The third most useful predictor is 'trust distributions - capital distributions in cash (to the HWI)' 7 Various other analyses were undertaken to confirm the stability of these results, and this flag also turned out to be important. For example, 'trust distributions - capital distributions in cash (to the HWI)' is rated over 7 and is the top predictor in a model predicting the sum of all risk ratings (0-10) across all 207 issues. Indeed all three flags in Table 3 are recurrently useful and statistically significant predictors across different types of analyses. Column two in Table 3 shows the Likelihood Chi Square statistic for the inclusion of the flag at each step of the model building process. Beyond this set of flags, although further flags were statistically significant, the increase in correctly predicted high risk HWIs was small.

The percentage in the fifth column of Table 3 shows that with information about whether each of these three issues is rated over 7 (and no other information about the case) we can correctly classify the case as High or not-High $91.9 \%$ of the time. Of the 202 HWIs in the low to medium risk group, 201 were correctly predicted. Of the 33 HWIs in the high risk group, 15 were correctly classified into the high risk group.

\footnotetext{
${ }^{6}$ The individual risks named in the data are loosely grouped under five broader risk categories. The broad risk categories are International, Losses, Group Structure, Miscellaneous Income \& Deduction Items, and Other Miscellaneous Items. The broad categories in turn contain more specific risk categories. Each of the specific risk categories contains a catch-all variable named 'other' to accommodate the less common or less understood risks of that type. As the broad category 'other miscellaneous items' has itself the flavour of a catch-all category, one would expect the least common or least understood risks of all to appear under the label 'other miscellaneous items - other'. Oddly, this has turned out to be the most highly predictive variable.

${ }^{7}$ In this sense 'capital' is the money contributed to set-up a business or keep it running. Unlike profit, it is not taxable when it is returned to the contributor (because it is assumed to have been taxed previously). There are obvious tax benefits to the HWI if they can re-characterise profit as capital.
} 
Table 3: Logistic regression: Prediction of high overall risk with issue risks rated over 7

\begin{tabular}{|l|l|l|l|l|l|}
\hline Step & Chi-square & df & Sig. & \% Correctly Classified & Flags \\
\hline 1 & 24.557 & 1 & 0.000 & $88.5 \%$ & $\begin{array}{l}\text { Other miscellaneous } \\
\text { items - other }\end{array}$ \\
\hline 2 & 21.402 & 1 & 0.000 & $90.6 \%$ & $\begin{array}{l}\text { Other miscellaneous } \\
\text { items - other } \\
\text { Use of an offshore } \\
\text { entity in an unlisted } \\
\text { country }\end{array}$ \\
\hline 3 & 14.894 & 1 & 0.000 & $91.9 \%$ & $\begin{array}{l}\text { Other miscellaneous } \\
\text { items - other } \\
\text { Use of an offshore } \\
\text { entity in an unlisted } \\
\text { country } \\
\text { Trust distributions - } \\
\text { capital distribution in } \\
\text { cash (to the HWI) }\end{array}$ \\
\hline
\end{tabular}

While it may seem obvious that these would be crucial issues, there may be any number of sets of completely different issues that would generate the same reaction. The question is which of the 207 risk issues we really would have selected as the top three predictors of overall risk. In our experience, auditors have hunches about red flags of risk that are in no way confirmed by this data. Some auditors believe that the use of a company controlled by a wealthy person to own a luxury yacht, a holiday home or a racehorse is a red flag. Although there is some support for this view from the data, knowledge of risk on any of these items classifies only two HWIs in the high risk group. Given the time it takes to get on top of the complexity of cases such as these groups of HWI entities, even very senior analysts may have a remarkably narrow scope of experience. While their supervisors might have greater breadth of experience built by approving the analyses of others, they lack the depth of experience of the analyst who has pored over the case. Hence a method that takes at face value that depth of experience, but aggregates it over the breadth of (235) cases, is valuable. Although less obvious, use of statistical reasoning also can produce results which are important though less intuitive. 


\section{Proxy analyses}

Although the three flags shown in Table 3 are statistically significant and useful in correctly predicting about half the HWIs in the high risk group, it is important to test if alternative sets of flags work equally well. There are many methods of looking for subsets. The method employed here is to remove the most significant from the potential set of flags used to predict high risk. Then the most significant flag from this analysis is removed from the potential pool of flags as well, and so on. This method also identifies the best predictors of high risk when used on their own. Further, there is the advantage of excluding the 'other miscellaneous items - other' issue from the potential pool of flags, since having a miscellaneous 'catch-all' issue as the best predictor of high risk can be difficult to interpret.

When 'other miscellaneous items - other' was excluded from the potential pool of flags, 'use of an offshore entity in an unlisted country' became the top predictor, followed by 'other significant deduction issues', a subheading of 'miscellaneous income and deduction items'. Interestingly, a slightly more specific catch-all issue has been substituted for another category of catch-all issue. 'Trust distributions - capital distributions in cash (to the HWI)' remained the third most significant predictor once these other flags were included (See Table 4). When 'other miscellaneous items - other' and 'use of an offshore entity in an unlisted country' were excluded from the pool of potential flags, 'trust distributions - capital distributions in cash (to the HWI)' became the top predictor, followed by 'miscellaneous income and deduction items - other significant deduction issues' (again) and another issue that looks like a proxy for 'use of an offshore entity in an unlisted country', that is, 'evidence of funds coming onshore irregularly' (as opposed to 'regularly').

When 'trust distributions - capital distributions in cash (to the HWI)' was removed from the pool of potential flags the 'utilisation of revenue losses via intra group transfers' (within the group of HWI entities) became the top predictor ${ }^{8}$. This means moving losses from one entity controlled by the HWI to wipe out or reduce the profits recorded in another entity it controls (or vice versa) so tax does not have to be paid on these profits.

\footnotetext{
${ }^{8}$ Also a top predictor when we predict the sum of all risk rankings (0-10) or the number of issues over 7 with the 1-10 risk score.
} 
Three new 'other' issues became the next best predictors of high risk: 'group structures - use of multiple entities (other)', 'group structures - evidence of value shifting/unusual transactions in group (other)' and 'other miscellaneous items - disposal of significant capital items (non-assessable profit)'. In our first proxy analysis an 'other' variable is replaced by a different 'other' variable. When this second 'other' is deleted from the analysis, two different kinds of 'other' variables are prominent in alternative sets 2 and 3. In short, as we delete one 'other' variable, another keeps popping up across all the proxy analyses. There is a stable 'other' effect.

Given also that Tables 1 and 2 show that the amount of money at risk in these 'other' issues is high, there is too much evidence to ignore this 'other' effect in an analysis of high risk and we need to consider whether there is some potentially explanatory meaning behind their significance.

Table 4: Proxy analysis: predicting high overall risk

\begin{tabular}{|l|l|l|}
\hline $\begin{array}{l}\text { Alternative set 1 } \\
\mathbf{9 1 . 1 \%} \text { correctly predicted }\end{array}$ & $\begin{array}{l}\text { Alternative set } \mathbf{2} \\
\mathbf{9 0 . 6 \%} \text { correctly predicted }\end{array}$ & $\begin{array}{l}\text { Alternative set } \mathbf{3} \\
\mathbf{8 9 . 4 \%} \text { correctly predicted }\end{array}$ \\
\hline $\begin{array}{l}\text { Use of an offshore entity in } \\
\text { an unlisted country }\end{array}$ & $\begin{array}{l}\text { Trust distribution - capital } \\
\text { distribution in cash (to the } \\
\text { MWI) }\end{array}$ & $\begin{array}{l}\text { Revenue loss utilisation via } \\
\text { intra group transfers }\end{array}$ \\
$\begin{array}{l}\text { Meduction items - other } \\
\text { significant deduction issues }\end{array}$ & $\begin{array}{l}\text { Miscellaneous income and } \\
\text { deduction items - other } \\
\text { significant deduction issues }\end{array}$ & $\begin{array}{l}\text { Other miscellaneous items - } \\
\text { disposal of significant } \\
\text { capital items in review } \\
\text { period (non-assessable } \\
\text { profit) }\end{array}$ \\
$\begin{array}{l}\text { distribution in cash (to the } \\
\text { HWI) }\end{array}$ & $\begin{array}{l}\text { Evidence of funds coming } \\
\text { onshore - irregularly }\end{array}$ & $\begin{array}{l}\text { Group structure - use of } \\
\text { multiple entities (other) }\end{array}$ \\
\hline
\end{tabular}


The four best predictors of overall high risk on their own are 'other miscellaneous items other', 'use of an offshore entity in an unlisted country', 'trust distributions - capital distributions in cash (to the HWI)' and the 'utilisation of revenue losses via intra group transfers'.

\section{Other risks and the evolutionary ecology of tax planning}

As would be expected with more than 200 possible risk labels, the number of HWIs rated above 7 in the 'other miscellaneous items - other' category is very small - only six HWIs. But all six have been assigned to the high risk group. This is very high when the probability of being in the high risk group for the whole data set is only 0.14. The Chi-square test of independence has a significance of less than five in a million that this result would have occurred by chance (exact significance level). One source of error in this calculation is that two HWIs who were related were both rated high for seemingly the same issue and thus independence is questionable. However the test would still remain very significant with the removal of either one of the relatives. Examination of the data also showed that the two HWIs who had the highest number of 'other miscellaneous items - other' type issues rated as a high risk were the two HWIs who also had the two greatest numbers of high risks. Overall eight per cent of the 207 issues were labelled as 'other' type issues and they were rated as a high risk eleven per cent of the time.

It is surprising that when more than 200 issues have been created to define the most important risks, some of the most worrying fall outside that list. This could be due to limitations in the type of risks included on the original risk identification form, or to the way analysts complete the form. For instance, they may have been confused by the way that their instructions conjoin 'further information desirable' with 'and would suggest audit action'. If insufficient information were available to properly assess an unusual issue they would be obliged to rate it as a high risk. Yet perhaps this unexpected outcome is not so surprising given the very nature of aggressive tax planning. Tax planning at its most aggressive is also at its most creative and entrepreneurial. The strategies that everyone, particularly the Tax Office, knows about will not be the most lucrative. When everyone is into the same aggressive tax planning strategy, the strategy will be highly visible and will draw the fire of the Tax Office. This will cause the smart money to move into more boutique strategies, and is a similar effect to the evolutionary ecology of predation in nature. While there are certain 
strategies of predation that can each inhabit a strong niche for predation, if all predators jumped into the same niche some would perish. It is thought that a new predation strategy is more likely to persist if it is different from that already used by other predators competing for the same resource (Cohen and Machalek, 1988). That is, under this scenario, the most successful strategies are those which are most idiosyncratic. Similarly with tax planning, the best tax planners are game players who are always coming up with new angles or games.

There is no single best strategy that all the smart money gravitates towards. Tax Office analysts commonly identify a set of strategies, which could be conceived in an evolutionary ecology of tax planning as standard niches, each of which support a lot of players. In Australia in recent years these have included:

- redefining income as capital by the use of multiple trust structures that conceal a common controlling mind;

- creating artificial losses, for example by acquiring companies or trusts with accumulated losses;

- disguising distributions to HWIs and family members as loans and other non-taxable benefits;

- using off-shore trusts;

- converting activities undertaken for private pleasure into tax losses (for example pleasure craft, horse breeding and racing);

- using charitable trusts to disguise benefits to HWIs and their families.

Aggressive tax planning is to a degree recurrent and patterned into the above standard forms.

However, it is also true that its leading edge is about finding new niches that are maximally lucrative because no one else is exploiting them and no law enforcers are watching them. At its most sophisticated, this leading edge involves engineering completely new financial 
products, mutations that are not covered by existing tax law (Tanzi, 2000). Faced with this evolution of tax planning, the belief that most aggressive tax planning in Australia is patterned into such stable and predictable niches could lead analysts to miss tax planning niches which pose the highest risk to the revenue. This could explain why a high risk under 'other miscellaneous items - other' would be both predictive of high risk overall and associated with maximum dollar amounts.

Is there evidence from the case files to support the notion that the 'other miscellaneous items - other' category, when rated as a high risk, indicates an innovative strategy, or was it rather that the analyst 'sensed' a risk not adequately covered by the predefined issues? Two cases were picked up by Penny Gilson of the HWI Taskforce with narratives identifying risks that could have (perhaps should have) been classified under one of the 207 risk categories. Without going back to the analysts and asking them to reconstruct their reasoning it is hard to be sure that they did not see an important additional risk that was not adequately captured by the pre-defined risk issues. One case narrative has, on the face of it, a jumble of concerns that seem over-rated and that suggest a lack of information more than systemic risk. Examples are:

'Overseas borrowing - group entity claimed deduction of $\$ 218000$ for interest paid to a Swiss financier.'

'Share trading - a group trust received substantial number of company $\mathrm{X}$ shares in float. Media reports indicate HWI made substantial profits through the sale of company $\mathrm{X}$ shares. Trust accounts do not reflect this amount.'

While the first example involves a small amount of money we do not know whether the analyst knows something about this financier that causes them to rate the risk as high. Perhaps the second example represents a kind of turning over of a seemingly inoffensive rock where something dangerous lurks. Perhaps the whole list of ten 'other' concerns conceals a detective's intuition about an inchoate underlying pattern of risk. We cannot be sure either way. For example, the HWI Taskforce staff suggested that in trying to make sense of losses,

\footnotetext{
${ }^{9}$ One risk that was classified as 'other' that was more or less systemic was property developers treating building costs as deductable on the revenue account while treating income from sales as capital. This practice gives the advantage of immediate deductions for expenses but a concessional treatment of income. It is not allowed by the legislation, but it appears that taxpayers 'try it on' in the hope the Tax Office will not detect it. It has since emerged that this practice is widespread among property developers.
} 
analysts might well say: 'There's a big loss but I'm not sure of the source. I'll put losses down as a risk. There is something else going on so I'll record it in the 'other' risk category. The case looks like a high risk overall. I'll get to the bottom of it when I audit them.' At the very least, we should read the strong predictive power of 'other miscellaneous items - other' as a caution about relying wholly on pre-defined risk issues for identifying aggressive tax planning. Rather, it encourages intuitive detective work to follow risks that fall between the cracks.

\section{Predicting the total number of high risks}

An alternative definition of high risk is the number of risks over 7 for a HWI. The question then becomes: if a particular risk issue is rated over 7, how many risk issues in total will be rated over 7? This is just another way of testing whether the existence of one kind of risk is a red flag for many different risks. We use a similar algorithm to that used for predicting high risk. The estimation procedure is ordinary least squares, and residual analysis was carried out to test the validity of assumptions important in this situation. Since the dependent variable in the model is a composite of all the potential independent variables (the flags) there is no attempt to use the statistical tests commonly associated with this type of modelling. The issue which when rated greater than 7 accounts for the most variance in this alternative definition of risk is included in the model first. Then the flag that accounts for the greatest proportion of the remaining variance is included, and so on until the amount of additional variance explained does not increase much relative to that already explained. The size of this change is determined by a scree slope test using $\mathrm{R}^{2}$.

The top predictor with this flag analysis is 'capital loss creation via by asset sales' (see Table 5). The second predictor is 'trust distributions - taxable distributions to a loss entity', another trust distributions issue. One of these issues is about creating losses and the other about shifting losses. This is the game of creating or buying losses and then avoiding tax by shifting value that would otherwise be taxed into an entity with losses that will cancel out their value. The number three predictor of the model in Table 5 is 'group restructures - significant new ventures'. This will often be rated as a risk because when new ventures are undertaken new entities are created that may be significant in terms of scale or in terms of moving offshore, or new in terms of being a new type of business for this group. Analysts may see reasons to worry that they may be connected to an aggressive tax planning scheme in the particular case. 
When we carry out a proxy analyses for this alternative definition of risk by dropping the top, second to top etc. predictor from the pool of potential flags, the conclusion is that little additional insight is afforded. 'Investments held off-shore in a listed country' is the top predictor if 'capital loss creation via asset sales' is removed from the potential flags. Unfortunately it may not be of practical significance as a red flag since only one HWI was rated a risk (greater than 7) on this issue. However not only was this HWI rated a high risk, they had the highest number of high risks (31); in fact one and a half times their nearest competitor (19) in terms of the number of high risks!

Table 5: Flags predicting the total number of issues rated over 7 - ordinary least squares regression*

\begin{tabular}{|l|l|}
\hline & Total $\mathbf{R}^{\mathbf{2}}$ \\
\hline Capital loss creation via asset sales & 0.38 \\
\hline Capital loss creation via asset sales & 0.55 \\
Trust distributions - taxable distributions to a loss entity & \\
\hline $\begin{array}{l}\text { Capital loss creation via asset sales } \\
\text { Trust distributions - taxable distributions to a loss entity }\end{array}$ & 0.67 \\
Group restructures - significant new ventures & \\
\hline
\end{tabular}

*Flags: Issues rated greater than 7 are coded 1, and zero otherwise.

The four best predictors when used on their own are 'capital loss creation via asset sales', 'bank accounts and investments held in a listed country' and 'taxable distributions to a loss entity', each accounting for approximately the same proportion of variance in the dependent variable.

\section{Using dollars at risk on a specific issue to predict high overall risk}

Table 6 shows the significant issues included in a model using dollars at risk to predict the probability of an overall high risk. As before, a forward stepwise logistic regression algorithm is used. However, issues were added to the predictive set until the likelihood ratio test for their inclusion was not significant. The analysis includes the implicit assumption that 
no dollars are at risk if a value is not recorded. This may not always be correct. The logistic model including the dollars at risk for the issues in Table 6 correctly predicts approximately 95\% of the HWI into their overall risk group. If we used a scree test slope as was done earlier, only three issues would have been shown and the percentage correctly predicted would have been 90.2 .

Table 6: Logistic regression: Prediction of high overall risk with dollars at risk

\begin{tabular}{|c|c|c|c|c|c|}
\hline Step & $\begin{array}{l}\text { Improvement in } \\
\text { chi-square at } \\
\text { each step }\end{array}$ & df & Sig. & $\begin{array}{l}\% \\
\text { correctly } \\
\text { predicted }\end{array}$ & Dollars at risk for issues \\
\hline 1 & 15.622 & 1 & 0.000 & $87.7 \%$ & $\begin{array}{l}\text { Trust beneficiary loan accounts - } \\
\text { credit balance and no draw-downs }\end{array}$ \\
\hline 2 & 12.540 & 1 & 0.000 & $88.5 \%$ & $\begin{array}{l}\text { +Trust distributions - capital } \\
\text { distributions in cash (to the HWI) }\end{array}$ \\
\hline 3 & 9.977 & 1 & 0.002 & $90.2 \%$ & $\begin{array}{l}\text { +Property held offshore in listed } \\
\text { country - real estate }\end{array}$ \\
\hline 4 & 9.408 & 1 & 0.002 & $90.6 \%$ & +Trust distributions to charitable trust \\
\hline 5 & 7.790 & 1 & 0.005 & $90.2 \%$ & $\begin{array}{l}\text { +Utilisation of revenue losses via } \\
\text { trading activities }\end{array}$ \\
\hline 6 & 5.348 & 1 & 0.021 & $90.6 \%$ & $\begin{array}{l}\text { +Related party transactions with an } \\
\text { entity in an unlisted country - royalty/ } \\
\text { license income }\end{array}$ \\
\hline 7 & 5.037 & 1 & 0.025 & $91.1 \%$ & $\begin{array}{l}\text { +Use of company shareholder loan } \\
\text { account - repayments by HWI }\end{array}$ \\
\hline 8 & 4.909 & 1 & 0.027 & $91.5 \%$ & $\begin{array}{l}\text { +Related party transactions with an } \\
\text { entity in an unlisted country - } \\
\text { provision of finance }\end{array}$ \\
\hline 9 & 9.422 & 1 & 0.002 & $93.2 \%$ & $\begin{array}{l}\text { +Revenue loss creation via debt } \\
\text { forgiveness/bad debts }\end{array}$ \\
\hline 10 & 5.262 & 1 & 0.022 & $93.2 \%$ & $\begin{array}{l}\text { +Trust distributions - capital } \\
\text { distribution in cash (to group entity) }\end{array}$ \\
\hline 11 & 11.708 & 1 & 0.001 & $94.9 \%$ & $\begin{array}{l}\text { +Utilisation of revenue losses via intra } \\
\text { group transfers }\end{array}$ \\
\hline
\end{tabular}

\footnotetext{
${ }^{10}$ Loan accounts are often used by HWIs as a tax free source of cash to maintain their lifestyles. A credit balance in a loan account would suggest that there was another source of income and analysts could find this a cause for concern.
} 
Most of the issues that make it into our final model (see Table 8) based on the subjective risk ratings do get some support from the more objective risk ratings data in Table 6. Having involvements in an offshore-unlisted country has multiple entries in Table 6. Trust distributions are there. 'Trust distributions - capital distributions in cash (to the HWI)' is the second highest objective predictor. ' JUtilisation of revenue losses via intra group transfers' is also present. Capital loss creation is not there, and neither is 'other miscellaneous items other'. Dollars at risk recorded in 'capital loss creation by asset sales' and 'other miscellaneous items - other' are actually significant predictors of high overall risk, but they are not as important as some of the others, nor are they as important in adding additional predictive information once some of the other issues are included in the model. All the HWIs who were given a high risk rating on 'other miscellaneous items - other' had zero or no dollars recorded, so it is not surprising this issue is not amongst the best.

There is interest also in issues that crop up in the dollar-based analysis that are not in the top predictive sets for the subjective rating analyses. The number three predictor, "property held offshore in a listed country - real estate', is an interesting one. It was also one of the best independent predictors of high risk when measured as the number of risks greater than 7 , but it did not outweigh the other predictors in Table 7. Why would the dollar value of offshore real estate investment not in a tax haven help to predict overall risk? Firstly we need to consider the data. There are only two HWIs with dollar amounts ever recorded for offshore real estate investment in an unlisted country, so it is not surprising that this issue was not included. However there are thirteen non-zero recorded dollar amounts for the issue 'property held offshore in a listed country - real estate' (twenty-eight HWIs were rated on this issue with two being rated as a high risk). The two largest dollar amounts were both HWIs where overall they were rated a high risk. This issue then, manages to capture just a few more of the high risk group over and above the first two issues in Table 6. On its own, or as is sometimes said, as a direct effect, it is only marginally significant with fifty other issues being more useful. Therefore although the dollars at risk for this issue adds additional predictive power to the model after the first two issues are included, it is not particularly useful in the predictive sense on its own. How far to speculate an explanation of the predictor is not a simple question. Usually, if the purpose of modelling is explanatory, then theoretical considerations would be used in defining a model rather than an algorithmic approach as used here. That

\footnotetext{
${ }^{11}$ Note also the predictive power of the dollar amounts of 'trust distributions - capital distributions in non-cash (to the HWI)' in Table 7.
} 
said, it may be reasonable to hypothesise a relationship of some sort between the finding that large real estate investment in a listed country is a high risk, and the earlier finding that a high risk rating for bank accounts and investments held in a listed country were two of the four best independent predictors of the total number of issues rated over 7 .

The fourth predictor shown in Table 6 - 'trust distributions to charitable trust' - is also not included in Tables 3 or 4 . In Table 7, where we use dollars at risk to predict the number of issues rated over 7, another issue neither in Table 3 nor 4 crops up, that is, 'revenue loss creation explained by negative gearing'. The HWI with the largest dollars on this issue, approximately $\$ 50$ million, was also rated overall a high risk, had the second largest number of high risk issues, and was rated high on 'other miscellaneous items - other'. Taking all this data together, although interesting, is likely to be indicative of the boutique strategies we mentioned earlier, rather than useful for identifying red flags of more general predictive value.

When we spoke to HWI Taskforce staff about these issues, their reaction was the same as ours: 'Analysts would not think this was a risk in itself'. However, there is the interesting question of whether tax planners exploit this reasonable kind of expectation. It may be that if you want to move an amount of money that is too large to hide, it is best to make it visible through a vehicle that makes it appear unexceptionable. Hence, it could be that having offshore real estate is not a risk factor, but placing huge amounts of money into these vehicles should put analysts on the alert. While negative gearing is a perfectly legitimate and normal commercial practice, extraordinarily large losses created by negative gearing may give reason to be watchful, though one might expect even aggressive players to exhaust legitimate deductions like negative gearing before moving on to more doubtful techniques.

Table 7 reports the predictor issues whose dollars at risk predict the number of high risk issues. One reason for these analyses is to see how well the dollars at risk for the different issues predict high risk, and which ones are the best predictors. Another reason is to provide a possible corrective for the subjective nature of the assessment of the ratings used in the first part of the paper. There is concern that there may be consistent analyst bias in the ratings data since both the aggregate estimates of risk (overall risk rating and number of high risk issues), and the estimate of risk on the issues, are a subjective assessment carried out by the same assessor and may be prone to the same bias. As a hypothetical example, consider the analyst 
who rates businessman $\mathrm{X}$ incorrectly high on certain issues because of bias or error; the same bias or error may result in the businessman being rated as a high risk overall. The role of the supervisor in these cases will eliminate some of the more obvious errors, but not all.

Table 7: Prediction of total number of risks rated above 7 using dollars at risk for each issue (ordinary least squares)

\begin{tabular}{|c|l|l|l|}
\hline Model & $\mathbf{R}^{\mathbf{2}}$ & $\begin{array}{l}\text { Adjusted } \\
\mathbf{R}^{\mathbf{2}}\end{array}$ & \\
\hline 1 & 0.503 & 0.501 & Revenue loss utilisation via intra group transfers \\
\hline 2 & 0.612 & 0.609 & $\begin{array}{l}\text { Revenue loss utilisation via intra group transfers } \\
\text { Revenue loss creation via negative gearing }\end{array}$ \\
\hline 3 & 0.677 & 0.673 & $\begin{array}{l}\text { Revenue loss utilisation via intra group transfers } \\
\text { Revenue loss creation via negative gearing } \\
\text { Trust distributions - capital distributions in non-cash (to the } \\
\text { HWI) }\end{array}$ \\
\hline 4 & 0.712 & 0.707 & $\begin{array}{l}\text { Revenue loss utilisation via intra group transfers } \\
\text { Revenue loss creation via negative gearing } \\
\text { Trust distributions - capital distributions in non-cash (to the } \\
\text { HWI) } \\
\text { Use of shareholder loan account - repayments by HWI }\end{array}$ \\
\hline 5 & 0.732 & 0.726 & $\begin{array}{l}\text { Revenue loss utilisation via intra group transfers } \\
\text { Revenue loss creation via negative gearing } \\
\text { Trust distributions - capital distributions in non-cash (to the } \\
\text { HWI) } \\
\text { Use of shareholder loan account - repayments by HWI } \\
\text { Trust distributions - capital distributions in cash (to HWI } \\
\text { family member) }\end{array}$ \\
\hline
\end{tabular}

It is difficult to know where to draw the line in our interpretations since often the number of cases is low, both in the number of issues where dollars at risk are recorded and the number of HWIs who are assessed as being a high risk. However the sparsity observed in this data set is very characteristic of rare events data. If the notion of an evolutionary ecology of tax planning with the occurrence of stable and new niches is apt, then the prediction of a small number of rare events is important to keep abreast of new strategies. 
The only issue that is listed in either Table 6 and 7 and the earlier tables where risk ratings were used is 'utilisation of revenue losses via intra group transfers'. This is actually the top predictor for the total number of issues rated over 7 (see Table 7). Since this is also recurrently predictive in the subjective analyses, 'utilisation of revenue losses via intra group transfers' was considered a definite contender for being a red flag issue. Of the 207 issues, it is also the one that most commonly has a high risk rating. This makes it a decidedly useful red flag for our final models.

\section{Choosing between subjective and dollar risk}

In practice it appears that the two types of analyses described, those using the estimates of risk rating and those using the dollars at risk estimates, are capturing different aspects of the risk prediction process.

Focusing on issues from the preceding tables, we examined the relationship between risk rating and dollar ratings. Although there is some evidence that the higher risks had higher dollars associated with them, it was by no means universal nor unambiguous as many issues had zero or low dollars associated with high risk and vice versa. Thus we need to interpret the dollars knowing that low dollars at risk do not necessarily signify low risk in the view of the assessor. This is just as was found for the dollars at risk for 'revenue loss creation via negative gearing' - assessors rarely considered the issue a high risk but unusually large dollars amounts recorded for this heading was predictive of high risk.

This report focuses on the subjective ratings and their use in predicting high risk. It is therefore of interest to ask if the dollars at risk for any issue adds significantly to the prediction after the flags from Table 3 have been included. This was analysed several ways and the dollars at risk for 'property held in a listed (non-tax-haven) country - real estate' consistently added to the prediction of high risk after subjective ratings were included. From our analyses it would appear that the subjective, informed assessment of the analyst is a useful approach to detecting risk, with the quantitative data providing further clues to follow. This is contrary to the notion that the dollars at risk, being a more objective measure, would be superior in its capacity to predict. 
Our experience of the regulatory craft (Sparrow, 2000) leads us to suspect that analysts need both the skills of a detective and those of an accountant. Nuance of judgment is needed; things have to pass the smell test. When the good analyst smells a rat, they are more likely to chase it down a hole than to further analyse numbers. While quantitative analysis provides clues, systemic wisdom must then be applied to the specific case. That case should be looked at through many different lenses, of which the quantitative lens is only one.

That said, this data suggests to us that there might be a case for a two-step process with aggressive tax planning analysis. Step 1 is a qualitative diagnosis of returns and other intelligence surrounding the case that is informed by knowledge of which are red flags of systemic risk to watch for. Step 2 is a re-examination of objectively unusually large amounts of money that occur under labels that are not viewed as red flags, but that might become red flags when the dollars in them are extraordinary. Step 2 does not mean further interrogation of all extraordinary amounts. It means a harder look only when exceptionally large amounts occur under non-red-flag issues that the kind of analysis in Tables 6 and 7 reveal to be significant predictors of overall risk.

This report only takes us as far as making some practical suggestions for the identification of red flags for step 1. Step 2 would only make sense to become a standard methodology after complementing the quantitative analysis in Tables 6 and 7 with qualitative intelligence on the operations of aggressive tax planners.

\section{Final red flag models}

Having carried out the above analyses, our final task is to convert the results shown in Tables 3 to 7 into a more useful form for discussion and practical application. It is clear that most of our potential red flags were consistent with what we referred to as standard niches. Other issues appeared to be indicative of more boutique niches. It has further been demonstrated that the number of HWIs rated as high on any one issue was small, which means that single high risk issues are a narrow basis for selecting cases for audit.

Could the results be made more useful for auditors by aggregating some of the issues that rarely occur as high risks? Consider 'capital loss creation via asset sales'. When the risk under this issue is rated high, the number of other risks rated over 7 averages 16 (compared to 
a mean of 0.86 when 'capital loss creation via asset sales' is not high). But there were only four HWIs with a rating over 7 on 'capital loss creation via asset sales', so the level of risk on this particular issue is sufficiently rare that it will be of limited value in audit practice.

So we created an aggregated issue of wider scope. This issue was 'capital loss creation' instead of the narrower (but more powerfully predictive) issue 'capital loss creation via asset sales'. The broader issue was a composite of nine different kinds of capital loss creation. Hence if there was a rating of more than 7 for any capital loss creation issue, the red flag was put up - whether the loss was created by asset sales, property development, debt forgiveness, bad debts, takeover/acquisition/merger, cost base manipulation, artificial loss duplication, related party transactions or some other explanation, or even if the capital loss creation was unexplained. Note however that it is not so broad as to include revenue loss creation; it is a capital loss creation variable only.

The second recurrently predictive red flag that we broadened was trust distributions. While 'trust distributions - capital distributions in cash (to the HWI)' was the most predictive red flag here, twenty different kinds of distributions from trusts were combined in the composite red flag. This included distributions in cash and non-cash to the HWIs themselves, to HWI family members, to group entities, to charitable trusts, to a loss entity, and from probate/deceased estates, related entities, and so on. There were from as well as to distributions. Finally we broadened 'other' to include all sixteen 'other' issues including 'other significant deduction issues', but not including 'miscellaneous income and deduction items'.

Table 8 shows the summary results from a logistic regression on high overall risk and an ordinary least squares regression predicting the total number of issues over 7 with our final set of red flags which include the broadened issues.

The adjusted $\mathrm{R}^{2}$ for the final red flags for predicting number of risks over 7 is an impressive $0.82^{12}$. Also using these same red flags to predict overall high risk, a slightly higher classification rate is obtained compared with the three predictors in Table 3. Thus these final aggregated red flags, which are arguably better for auditing purposes, do as well or better

\footnotetext{
${ }^{12} \mathrm{An} \mathrm{R}^{2}$ of 0.82 means that $82 \%$ of the statistical variance is explained.
} 
than our previous sets of red flags. Therefore, there appears to be value for auditors in aggregating up some of the issues that rarely occur as high risks.

Analysis of the details shows that the final red flag model actually correctly predicts more HWIs into the high risk group but at the expense of incorrectly predicting some of the other HWIs as being high risk. The flag 'utilisation of revenue losses via intra group transfers', although significant, is not particularly useful in classifying the overall risk group, but it does significantly increase the amount of variance explained when predicting the number of high risks.

Table 8: Summary results of the models for predicting risk using the final red flags

\begin{tabular}{|l|l|l|}
\hline \multirow{2}{*}{$\begin{array}{l}\text { Flags } \\
\text { (Number of HWIs with high risk) }\end{array}$} & $\begin{array}{l}|c| \\
\text { Predicting overall high } \\
\text { risk - logistic regression }\end{array}$ & $\begin{array}{l}\text { Predicting number of } \\
\text { high risks - ordinary } \\
\text { least squares regression }\end{array}$ \\
\cline { 2 - 3 } $\begin{array}{l}\text { Other categories (20) } \\
\text { unlisted country (8) }\end{array}$ & $92.8 \%$ & $\mathrm{R}^{2}=0.90$ \\
$\begin{array}{l}\text { Capital loss creation (11) } \\
\text { Group trust distributions (16) }\end{array}$ & $\begin{array}{l}\text { correctly predicted } \\
\text { the low to medium risk } \\
\text { Utilisation of revenue losses via } \\
\text { intra group transfers (12) }\end{array}$ & $\begin{array}{l}\text { group } 22 \text { HWI out of } \\
33 \text { of the high risk group } \\
\text { correctly predicted. }\end{array}$ \\
\hline
\end{tabular}

Hence we have identified five final red flags for overall risk:

- trust distributions;

- capital loss creation;

- use of an offshore entity in a country that may be a tax haven;

- utilisation of revenue losses via intra group transfers; and

- extraordinary risks that fall between the cracks of the other risks. 
Analysis showed that the five subjective red flags were of more importance in predicting high overall risk than any of the dollar amounts associated with the red flags. The only red flag where the associated dollars at risk added significant extra predictive information above that of the subjective ratings greater than 7 was 'utilisation of revenue losses via intra group transfers'. This was only the case for the model predicting number of risks greater than 7 .

\section{Conclusion}

The five red flag issues identified in this report are consistent with what many would regard as the fundamentals of aggressive tax planning. They are:

- trust distributions (especially capital distributions in cash to the HWI);

- capital loss creation (especially through asset sales, but not revenue loss creation);

- use of an offshore entity in a country that may be a tax haven;

- utilisation of revenue losses via intra group transfers (that is, within the group of entities controlled by the HWI), and

- 'other' extraordinary risks that fall between the cracks.

The results on the 'other' measures may suggest that we do not always know what the emerging fundamentals of the future may be. Thus it is suggested that creative openness is necessary in aggressive tax planning enforcement. In other words, it is important to look between the cracks of what are thought to be the fundamentals of aggressive tax planning.

An evolutionary ecology of tax planning implies that some successful players will seek new niches. Financial engineering of new derivatives never conceived before by tax law and global capital mobility make this more possible than in the past (Department of the Treasury, 1999). As the law adapts to close off new niches the change in the tax law environment may also create new niches for other tax strategies. Law makers are less and less able to control these unintended effects as tax law changes in other countries create new niches available to local aggressive tax planners. The aggressive tax planner benefits from both an expanding range of niches globally, and expanding technical capabilities for local financial engineering. The first four red flags listed here may cover the standard niches while the last one covers the new niches. 
The analyses also suggest that cases where extraordinary dollar amounts are seen under issues that are not normally red flags, especially for cases where other red flags suggest systemic risk, should be examined closely to see if there is evidence of new and previously unseen strategies or niches.

Some aspects of the red flags we have identified should cease being indicators of risk to the revenue in future as Australian tax reforms have been undertaken to specifically deal with some of these problems. To this extent, the findings suggest that tax reform was well directed. For instance, the new loss integrity measures should prevent the 'cascading' of losses and will address some but not all loss creation issues. The proposed consolidation measures are intended to limit the 'trafficking' of losses from outside the company (but they will not affect the genuine transfer of losses as this is accepted as part of normal business practice).

The proposed entity taxation regime, if adopted, will tax non-fixed trusts as companies and treat trust distributions as dividends which would remove much of the tax effectiveness of trusts. This regime, however, has been put on hold for at least 12 months. While not such a recent development, the controlled foreign corporations law was introduced to deal with tax haven use. Initially payments to these countries decreased but the latest Tax Office annual report notes that transfers to tax havens have increased significantly since 1996. Perhaps some aggressive tax planners have found a way of circumventing this legislation. In any case it appears that tax haven use remains a high risk area (Tanzi, 2000).

In a dynamic ecology of aggressive tax planning enforcement, tax administrators must adapt to cut out old risk factors just as they must prepare for mutations into new ones. Some of the most recurrent forms of aggressive tax planning are variations on fundamental themes that have been with us for many decades. Yet many of the mutations that seem so new retain the character of those fundamental strategies. A clever new piece of financial engineering may be clever and new at the same time as it is just another way of shifting losses, even if it cannot be recognised at first as loss shifting. 


\section{REFERENCES}

Braithwaite, J. (2001), Through the Eyes of the Advisers: A Fresh Look at the Compliance of High Wealth Individuals. Centre for Tax System Integrity Working Paper, Australian National University: Canberra.

Cohen, Lawrence E. and Richard Machalek (1988), 'A General Theory of Expropriative Crime: An Evolutionary Ecological Approach,' American Journal of Sociology. 94: 465-501.

Commissioner of Taxation (2000), Commissioner of Taxation Annual Report 1999/2000. Commonwealth of Australia: Canberra

Department of the Treasury (1999), The Problem of Corporate Tax Shelters: Discussion, Analysis and Legislative Proposals. Dept. Of the Treasury: Washington, D.C.

Sparrow, M. (2000), The Regulatory Craft. Washington, D.C.: Brookings Institution.

Tanzi, Vito (2000). 'Globalization, Technological Developments, and the Work of Fiscal Termites'. IMF Working Paper WP/00/11811. Washington, DC: International Monetary Fund. 


\section{THE CENTRE FOR TAX SYSTEM INTEGRITY WORKING PAPERS}

No. 1. Braithwaite, V. \& Reinhart, M. The Taxpayers' Charter: Does the Australian Taxation Office comply and who benefits? December 2000.

No. 2. Braithwaite, V. The Community Hopes, Fears and Actions Survey: Goals and Measures. March 2001.

No. 3. Braithwaite, V., Reinhart, M., Mearns, M. \& Graham, R. Preliminary findings from the Community Hopes, Fears and Actions Survey. April 2001.

No. 4. Mearns, M., \& Braithwaite, V. The Community Hopes, Fears and Actions Survey: Survey method, sample representativeness and data quality. April 2001.

No. 5. Sakurai, Y., \& Braithwaite, V. Taxpayers' perceptions of the ideal tax adviser: Playing safe or saving dollars? May 2001.

No. 6. Wenzel, M. The impact of outcome orientation and justice concerns on tax compliance: The role of taxpayers' identity. June 2001.

No.7. Wenzel, M. Misperceptions of social norms about tax compliance (1): A prestudy. June 2001.

No. 8. Wenzel, M. Misperceptions of social norms about tax compliance (2): A fieldexperiment. June 2001.

No.9. Taylor, N. Taxpayers who complain about paying tax: What differentiates those who complain from those who don't? June 2001.

No. 10. Wenzel, M. Principles of procedural fairness in reminder letters and awareness of entitlements: A prestudy. June 2001.

No. 11. Taylor, N. \& Wenzel, M. The effects of different letter styles on reported rental income and rental deductions: An experimental approach. July 2001.

No. 12. Williams, R. Prosecuting non-lodgers: To persuade or punish? July 2001.

No. 13. Braithwaite, V. Tensions between the citizen taxpaying role and compliance practices. Forthcoming.

No. 14. Taylor, N. Understanding taxpayer attitudes through understanding taxpayer identities. July 2001.

No. 15. Shover, N., Job, J. \& Carroll, A. Organisational capacity for responsive regulation. August 2001. 
No. 16. Tyler, T.R. Trust and law-abidingness: A proactive model of social regulation. August 2001.

No. 17. Genser, B. Corporate income taxation in the European Union: Current state and perspectives. August 2001.

No. 18. McBarnet, D. When compliance is not the solution but the problem: From changes in law to changes in attitude. August 2001.

No. 19. Schneider, F., Braithwaite, V. \& Reinhart, M. Individual behaviour in Australia's shadow economy: Facts, empirical findings and some mysteries. September 2001.

No. 20. Taylor, N. \& Wenzel, M. Comparing rental income and rental deductions for electronic versus paper lodgers: A follow-up investigation. Forthcoming.

No.21. Braithwaite, J. Through the eyes of the advisers: A fresh look at tax compliance of high wealth individuals. September 2001.

No. 22 Braithwaite, J., Pittelkow, Y. \& Williams, R. Tax Compliance by the very wealthy: Red flags of risk. September 2001. 